\title{
Puesta a punto del método de PCR en tiempo real para la cuantificación de Aspergillus carbonarius en uvas Vitis vinifera cv. Tannat
}

\author{
Garmendia, G. ${ }^{(1)} *$, Vero, S. ${ }^{(1)}$ \\ (1) Cátedra de Microbiología, Departamento de Biociencias. Facultad de Química, Universidad de la República, Uru- \\ guay. \\ Contacto: garmendia $@$ fq.edu.uy
}

Recibido: 30/06/2011 - Aprobado: 7/11/2011

\begin{abstract}
$\underline{\text { Resumen }}$
La ocratoxina A (OTA) es una micotoxina que ha sido detectada en uvas y vinos. Es producida por Aspergillus ochraceus, Penicillium verrucosum, Aspergillus carbonarius y especies pertenecientes al agregado Aspergillus niger. En los últimos años se ha descrito la presencia de Aspergillus aculeatus y Aspergillus japonicus en la superficie de uvas y su capacidad de producir OTA. A pesar de que la concentración detectada de cepas pertenecientes a la Sección Nigri fue $<100 / g$ de uva, se han aislado, identificado y caracterizado 56 cepas de Aspergillus pertenecientes a la Sección Nigri. El $51 \%$ fue identificado como A. niger, el $39 \%$ como A. japonicus, $5 \%$ como A. tubingensis -like y $5 \%$ como A. foetidus. Ninguna cepa de A. carbonarius fue aislada. Debido a que esta especie ha sido descrita como la principal responsable de la presencia de OTA en uvas y vinos por su capacidad de producir altas concentraciones de OTA, se requiere un método más sensible que los métodos convencionales para detectar y cuantificar la presencia de A. carbonarius en uva. En este trabajo se optimizó la técnica de PCR en tiempo real para la detección y cuantificación de esta especie en uvas de la variedad Tannat.

Palabras clave: Ocratoxina A, Sección Nigri, uva
\end{abstract}

\begin{abstract}
$\underline{\text { Abstract }}$
Ochratoxin A has been detected in grapes and wines. It is produced by Aspergillus ochraceus, Penicillium verrucosum, Aspergillus carbonarius, species belonging to Aspergillus niger aggregate. During the last yars the presence of Aspergillus aculeatus and Aspergillus japonicus in grape surface and its ability to produce OTA has been reported. Our research group isolated, identified and characterized 56 Aspergillus strains; $51 \%$ was identified as A. niger, $39 \%$ as A. japonicus, $5 \%$ as A. foetidus, and $5 \%$ as $A$. tubingensis like. None A. carbonarius was isolated. This species have been reported as the principal source of OTA in wine grapes and wines due to its ability to produce high mycotoxin concentrations on fruit. Thus, a more sensitive method to quantify A. carbonarius would be important to ensure the absence of this pathogen in grape samples. In this work Real Time PCR for quantification of A. carbonarius in Tannat grapes was optimized.

Keywords: Ochratoxin A, Section Nigri, grape
\end{abstract}

\section{Introducción}

Presentes como contaminantes de alimentos, las micotoxinas se han convertido en un gran problema para la salud humana y animal. En particular, la ocratoxina A (OTA) ha sido detectada en alimentos como cocoa, café, cereales y legumbres (Serra y Bonhevi, 2004; Vatinno et al., 2008; Mateo et al., 2007; Juan et al., 2008) y en bebidas como cerveza y vinos (Battilani et al., 2006; Chulze et al., 2006; Ponsone et al., 2007). Según Miraglia y Brera (2002), el vino es el segundo responsable de ingesta de OTA en Europa.

La OTA tiene efectos nefrotóxicos, carcinogénicos, teratogénicos e inmunosupresivos y ha sido asociada a la Nefropatía Endémica de los Balcanes (López de Cerain et al., 2000). A su vez, la Agencia Internacional de Investigación en Cáncer la ha clasificado dentro del grupo 2B, probable carcinogénico en humanos (IARC, 1993). Su principal mecanismo de acción es la inhibición de síntesis proteica. Compite con la fenilalanina en la unión con el ARN de transferencia, provocando la carencia de determinadas enzimas (López de Cerain et al., 2000).
La OTA es producida por especies de los géneros Penicillium y Aspergillus. Dentro del género Penicillium, la única especie productora es $P$. verrucosum (Ostenfeld et al., 2001), mientras que dentro del género Aspergillus han sido descritas como productoras cepas de A. ochraceus y especies de la Sección Nigri, tanto monoseriadas (A. japonicus y A. aculeatus) como biseriadas (A. carbonarius, A. tubingensis, A. foetidus, A. niger y A. brasiliensis) (Abarca et al., 2004; Ponsone et al., 2007). Sin embargo, las cepas de la especie $A$. carbonarius son las principales causantes de la presencia de OTA en vinos, debido a su capacidad de producir altas concentraciones de esta toxina en uva (Bau et al., 2004; Serra et al.; 2006).

En 2005 la Organización Internacional de la Viña y el Vino (OIV) estableció un límite máximo de 2 ppb para esta toxina en vino (Resolución CST 1/2002). Es por esto que la presencia de OTA en vinos uruguayos puede llegar a convertirse en una barrera no arancelaria, provocando una disminución en las exportaciones y, por consiguiente, una disminución en los ingresos del sector.

En 2006 nuestro grupo de investigación comenzó a estudiar la presencia de posibles cepas productoras de OTA en uvas para la 
producción de vino. Se aislaron un total de 56 cepas de Aspergillus pertenecientes a la Sección Nigri. Estas cepas fueron identificadas fenotípica y molecularmente y caracterizadas respecto a su capacidad de producir OTA. Todas las cepas aisladas fueron productoras de OTA en las condiciones del ensayo, la mayoría pertenecientes a las especies A. japonicus y A. niger.

En ninguno de los casos las cepas de Aspergillus fueron flora predominante. Por el contrario, se puede decir que en la mayoría de los casos su concentración fue menor a 100ufc/g uva. Sin embargo, estos valores no eliminan el riesgo de presencia de OTA en vino, ya que, según Díaz et al. (2009), partiendo de un $0.5 \%$ de uvas contaminadas con Aspergillus carbonarius se obtiene un vino con niveles de OTA que superan el límite máximo de contaminación aceptado por la OIV. Estas evidencias hacen necesario un método sensible para la cuantificación de inóculo sobre la uva utilizada como materia prima que permita predecir el riesgo de contaminación con OTA del vino que se elabora. Este trabajo plantea la puesta a punto de un método de PCR en tiempo real para la cuantificación de $A$. carbonarius sobre uva variedad Tannat. La investigación se centró en esta variedad dado que se trata de la uva emblemática de Uruguay y porque a nivel mundial no se han encontrado datos sobre el estudio de la contaminación de esta variedad de uva con cepas ocratoxigénicas.

\section{Materiales y Métodos}

\section{Cepas utilizadas}

Para la puesta a punto del método de PCR en tiempo real se utilizó la cepa Aspergillus carbonarius CBS 111.26, perteneciente a la colección holandesa del Central Bureau voor Schimmelcultures (CBS). Las restantes cepas de la Sección Nigri utilizadas pertenecieron a las especies A. niger, A. foetidus, A. tubingensis like y A. japonicus. Estas cepas fueron aisladas de uvas uruguayas por este grupo de investigación e identificadas genotípicamente mediante secuenciación de la región ITS1-ITS2 y de parte del gen que codifica para la camodulina.

\section{Extracción de ADN}

Las cepas fueron cultivadas en $10 \mathrm{~mL}$ de YES (2\% extracto de levadura, $15 \%$ sacarosa) a $25{ }^{\circ} \mathrm{C}$ durante 5 días. Luego del tiempo de incubación una porción del micelio se trasvasó a un tubo de microcentrífuga estéril de $2 \mathrm{~mL}$ y se molió hasta polvo fino en presencia de nitrógeno líquido utilizando una varilla de vidrio. A partir del micelio molido se extrajo el ADN total mediante la utilización del kit comercial DNeasy Plant Mini Kit (Qiagen). El ADN obtenido se visualizó mediante electroforesis en gel de agarosa $0.8 \%$ con bromuro de etidio como indicador. El gel se reveló bajo una lámpara UV (Sambrook et al., 1989).

\section{Puesta a punto de PCR en tiempo real para la cuantificación de $A$. carbonarius}

El método de PCR en tiempo real se realizó de acuerdo a González Salgado (2010) y González Salgado et al. (2009). Los primers utilizados fueron QCarbo1 (5'- GGGCTTTGTCACATGCTCTGTA 3') y QCarbo2 (5' - CTGGAAAAAAAGGTTGGAGTTGTC - 3'), sintetizados por SBS Genetech Co., Ltd (Beijing, China). La reacción de PCR en tiempo real transcurrió en un volumen de reacción de 10 $\mu \mathrm{L}$ con $5 \mu \mathrm{L}$ de mix Rotor gene SyBr Green PCR kit (Qiagen), $1 \mu \mathrm{L}$ de cada primer de concentración $5 \mu \mathrm{M}, 0.5 \mu \mathrm{L}$ de agua miliQ estéril y $2.5 \mu \mathrm{L}$ de ADN. El ciclo de amplificación consistió en un ciclo inicial de 10 minutos a $95^{\circ} \mathrm{C}$, seguido por 40 ciclos de 15 segundos a $95^{\circ} \mathrm{C}$ y
1 minuto a $60^{\circ} \mathrm{C}$. La reacción se llevó a cabo en un equipo RotorGene 6000 , Corbett Life Science.

\subsection{Especificidad de los primers por PCR convencional}

Los primers Qcarbo1 y Qcarbo2 fueron enfrentados a las cinco especies de la Sección Nigri (A. carbonarius, A. foetidus, A. niger, A. tubingensis-like y $A$. japonicus) en una reacción de PCR de volumen final $25 \mu \mathrm{L}$ de acuerdo a las siguientes condiciones: $2,5 \mu \mathrm{L}$ Buffer 10X (Fermentas International INC., Canada), $16,9 \mu \mathrm{L}$ de agua miliQ estéril, $1 \mu \mathrm{L}$ de cada primer $5 \mu \mathrm{M}, 2,5 \mu \mathrm{L}$ de dNTP $2 \mu \mathrm{M}, 0,1 \mu \mathrm{L}$ de Taq polimerasa (Fermentas International INC., Canada) $5 \mathrm{u} / \mu \mathrm{L}$ y $1 \mu \mathrm{L}$ de $\mathrm{ADN}$ de concentración $90 \mathrm{ng} / \mu \mathrm{L}$. El ciclo de amplificación consistió en 35 ciclos de $95{ }^{\circ} \mathrm{C} 1 \mathrm{~min}, 60{ }^{\circ} \mathrm{C} 1 \mathrm{~min}, 72{ }^{\circ} \mathrm{C} 2 \mathrm{~min}$. La amplificación se realizó en un termociclador MultiGene Mini Labnet International, INC. (Edison, NJ, USA). El producto de PCR fue detectado mediante electroforesis en gel de agarosa $0.8 \%$ con bromuro de etidio como indicador. El gel se reveló bajo una lámpara UV (Sambrook et al., 1989).

\subsection{Curvas estándar}

El ADN genómico de $A$. carbonarius fue cuantificado utilizando el fluorímetro Qubit 2.0 (Invitrogen). Se realizaron diluciones seriadas en base diez de la solución del ADN genómico en agua. El rango de concentraciones utilizado fue entre $2.7 \times 10^{-5}$ y $0.27 \mathrm{ng} / \mu \mathrm{L}$. Para cada concentración de ADN se llevó a cabo la PCR en tiempo real. Paralelamente se realizó un blanco conteniendo agua miliQ estéril. Cada concentración de ADN se ensayó por triplicado. Para cada caso se determinó el Cycle thershold $(\mathrm{Ct})$.

A partir de los valores de $\mathrm{Ct}$ de cada concentración se realizó una curva de calibración graficando $\mathrm{Ct}$ en función del logaritmo de la concentración de ADN. Se determinó la linealidad, la eficiencia y el rango dinámico.

\subsection{Especificidad de los primers en PCR en tiempo real}

La PCR en tiempo real descrita anteriormente se realizó también para una cepa de $A$. niger y una cepa de $A$. japonicus. Para ambos casos, se cuantificó ADN genómico con el fluorímetro Qubit 2.0 (Invitrogen) y se realizaron las diluciones correspondientes de forma de abarcar las mismas concentraciones de ADN ensayadas para la cepa de A. carbonarius. En ambos casos se incluyó un blanco y una concentración de $A$. carbonarius como control positivo. Se determinó Ct de cada concentración.

\subsection{Influencia de la matriz PCR en tiempo real}

Para el estudio de la matriz se ensayó la técnica de extracción de ADN para una muestra de $3 \mathrm{~g}$ de uva Tannat. Al extracto obtenido se añadieron diferentes cantidades de ADN genómico de $A$. carbonarius y cada muestra se sometió a PCR en tiempo real. En paralelo se incluyó un blanco y diluciones realizadas con agua de forma de comparar los Ct obtenidos en cada caso y de esta forma determinar inhibición por la matriz.

\section{Resultados}

Se comprobó la especificidad de los primers tanto en la PCR convencional como en la PCR en tiempo real. En el primer caso se observó amplificación de un fragmento de 66 pb sólo en el caso de A. carbonarius, en tanto que para las especies $A$. niger y $A$. japonicus 
el Ct obtenido en PCR en tiempo real fue muy cercano al correspondiente al blanco. En la Figura 1 se observa la curva obtenida para dos concentraciones de $A$. carbonarius ( $0.27 \mathrm{ng}$-a-, y $0.0027 \mathrm{ng}$-b-), las curvas obtenidas para las concentraciones del mismo orden de $A$. niger y A. japonicus y dos repeticiones del blanco (conjunto c). En la Tabla 1 se detallan varias concentraciones de A. niger y A. japonicus ensayadas y los Ct obtenidos, comparados con el blanco.

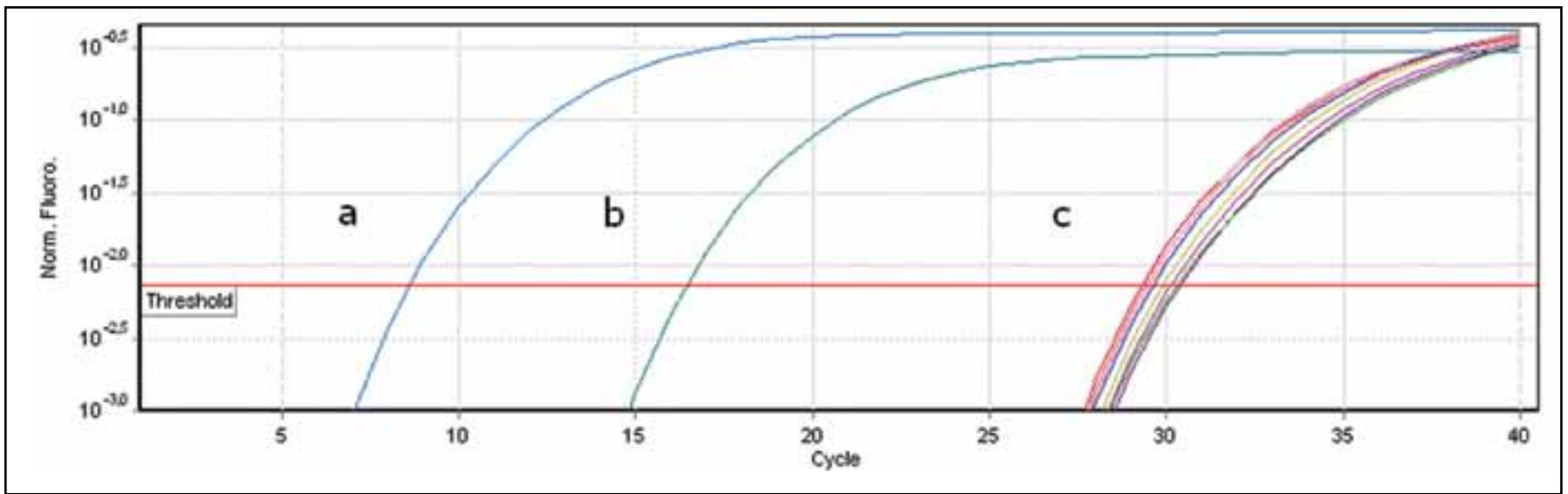

Figura 1. PCR en tiempo real para A. carbonarius (a y b), A. japonicus y A. niger (c)

\begin{tabular}{|c|c|c|}
\hline ng ADN & Ct $\boldsymbol{A}$. niger & Ct A. japonicus \\
\hline 0,12 & $27,1 \pm 2,3$ & $31,8 \pm 3,7$ \\
\hline 0,012 & $30,8 \pm 0,4$ & $32,2 \pm 3,7$ \\
\hline 0,0012 & $31,1 \pm 2,71$ & $32,3 \pm 3,7$ \\
\hline $1,2 \times 10^{-4}$ & $33,4 \pm 2,8$ & $28,7 \pm 1,3$ \\
\hline blanco & $29,5 \pm 0,9$ & $29,5 \pm 0,9$ \\
\hline
\end{tabular}

Tabla 1.Comparación entre Ct $A$. niger y Ct $A$. japonicus

Las curvas estándar obtenidas para la cuantificación de $A$. carbonarius (Figura 2) presentaron una linealidad $(\mathrm{r} 2=0.997)$ y eficiencia $(107 \%)$ dentro de lo esperado. El rango dinámico se definió entre $0.27 \mathrm{ng}$ y 2.7 x $10-5 \mathrm{ng}$, ya que para cantidades de ADN superiores o inferiores la curva de calibración perdía linealidad. Las barras de error de la Figura 2 representan los intervalos de confianza de cada punto. En todos los casos el error no superó el $1.3 \%$ del valor.

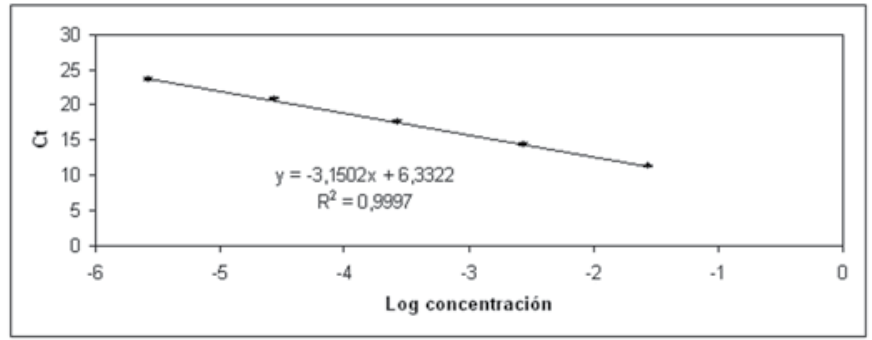

Figura 2. Curva estándar de cuantificación de A. carbonarius

La Tabla 2 muestra los resultados del análisis de la influencia de la matriz en el método. No se observó inhibición por la matriz en estudio en las condiciones del ensayo, ya que el Ct obtenido en presencia de extracto de uva fue similar al Ct obtenido en presencia de agua, y las diferencias de $\mathrm{Ct}$ se encontraron dentro del error del método.

\begin{tabular}{|c|c|c|}
\hline ng ADN & Ct uva & Ct agua \\
\hline 0,27 & 11,42 & 11,35 \\
\hline 0,0027 & 17,13 & 17,63 \\
\hline blanco & 27,87 & 28,90 \\
\hline
\end{tabular}

Tabla 2. Influencia de la matriz en la PCR en tiempo real. 


\section{Discusión}

El método puesto a punto fue específico para $A$. carbonarius. La fluorescencia generada con las especies $A$. niger y $A$. japonicus no mostró diferencias significativas con respecto al blanco, para todas las concentraciones ensayadas. Se postula que la fluorescencia generada a estos valores de Ct podría deberse a hibridación de primers.

Este resultado es de gran importancia, dado que las principales especies contaminantes de uva uruguaya resultaron $A$. niger y $A$. japonicus y, por ende, asegura que en uva no habrá cuantificación inespecífica en ausencia de $A$. carbonarius. Por otro lado, los primers utilizados en este ensayo fueron diseñados dentro de la región de ITS1-ITS2. La secuencia de esta región permite diferenciar entre $A$. carbonarius, el agregado A. niger y las especies monoseriadas de la Sección Nigri. El porcentaje de similitud entre las especies del agregado A. niger en esta región es cercano al $100 \%$, al igual que entre las especies de monoseriadas. Esto indicaría que si una especie perteneciente al agregado $A$. niger o una especie monoseriada de la Sección no genera fluorescencia durante la reacción de PCR en tiempo real, ninguna de las otras especies pertenecientes a cada grupo debería generarla. Es por este motivo que en el estudio de especificidad de los primers en la PCR en tiempo real se eligió un especie de cada grupo (A. niger y A. japonicus).

Con respecto a la eficiencia, para un método de PCR en tiempo real se espera que la misma esté entre 90 y $110 \%$ (Rebrikov et al., 2006). En el caso de este trabajo la eficiencia se encontró dentro de este rango, por lo cual se puede inferir que la amplificación ha funcionando correctamente, sin interferencias. Con respecto al rango dinámico, el límite inferior del método fue de $2.7 \times 10^{-5} \mathrm{ng}$. De acuerdo a Selma et al. (2008), una conidia de A. carbonarius contiene 3.15 x $10^{-5} \mathrm{ng}$ de $\mathrm{ADN}$, lo que permite afirmar que el límite mínimo de detección del método es menor a una conidia.

Por último, este método no presenta inhibición por la matriz; la fluorescencia generada en presencia de extracto de uva de la variedad Tannat es la misma que en presencia de agua, por lo que se trata de un método que podría ser aplicable para la cuantificación de $A$. carbonarius en uvas Tannat naturalmente contaminadas. El uso de este método haría posible predecir el riesgo de contaminación con OTA del vino elaborado a partir de la uva analizada, lo cual ayudaría a la bodega a tomar medidas preventivas a la hora de la elaboración.

\section{Agradecimientos}

Este trabajo fue realizado gracias a una Beca de posgrado LATUFacultad de Química y PEDECIBA Química.

\section{Referencias}

- ABARCA, M.L.; ACCENSI, F.; CANO, J.; CABAÑES, F.J. Taxonomy and significance of black aspergilli. En: Antonie van Leewenhoek. 2004, 86:33-49.

- BATTILANI, P.; MAGAN, N.; LOGRIECO, A. European research on ochratoxin A in grapes and wine. En: International Jouirnal of Food Microbiology. 2006, 111(1):S2-S4.

- BAU, M.; BRAGULAT, M.R.; ABARCA, M.L.; MINGUEZ, S.; CABAÑES, F.J. Ochratoxigenic species from Spanish wine grapes. En: International Journal of Food Microbiology. 2004, 98(2):125130.

- CHULZE, S.N.; MAGNOLI, C.E.; DALCERO, A.M. Occurrence of ochratoxin A in wine and ochratoxigenic mycloflora in grapes and dried vine fruits in South America. En: International Journal of Food Microbiology. 2006, 111(1):S5-S9
- DÍAZ, G.A.; TORRES, R.; VEGA, M.; LATORRE, B.A. Ochratoxigenic Aspergillus species on grapes from Chilean vineyards and Aspergillus threshold levels on grapes. En: International Journal of Food Microbiology. 2009, 133(1-2):195199

- GONZÁleZ SAlgADO, A. Diagnóstico y control de especies de Aspergillus productoras de ocratoxina A. Madrid: Universidad Complutense de Madrid, 2010. (Tesis Doctoral)

- GONZÁleZ SALGADO, A.; PATIÑO, B.; GIL-SERNA, B.; VAZQUEZ, C.; GONZALEZ JAÉN, M.T. Specific detection of Aspergillus carbonarius by $\mathrm{SYBr}$ green and TaqMan quantitative PCR assays based on the multicopy ITS2 region of the rRNA gene. En: FEMS Microbiological Letters. 2009, 295 : 57-66

- IARC-INTERNATIONAL AGENCY FOR RESEARCH ON CANCER. Monographs on the evaluation of carcinogenic risk to human. Paris: IARC, 1993. 56:489-521.

- JUAN, C.; MOLTÓ, J.C.; LINO, C.M.; MAÑES, J. Determination of ochratoxin A in organic and non organic cereals and cereal products from Spain and Portugal. En: Food Chemistry. 2008, 107(1):525-530.

- LÓPEZ DE CERAIN, A.; JIMÉNEZ, A.M.; EZPELETA, O.; BELLO, J. Efectos tóxicos de la ocratoxina A. En: Revista de Toxicologi: 2000, 17:61-69.

- MATEO, R.; MEDINA, A.; MATEO, E.M.; MATEO, F.; JIMÉNEZ, $\mathrm{M}$. An overview of ochratoxin A in beer and wine. En: International Journal of Food Microbiology. 2007, 119 (1-2):79-83

- MIRAGLIA, M.; BRERA, C. Assessment of dietary intake of ochratoxin $A$ by the population of EU member states. Bruselas: Directorate-General Health and Consumer Protection, 2002. (Report on Tasks for Scientific Cooperation)

- OIV. Resolución CST 1-2002 reducción de Ocratoxina A en los vinos. Paris: OIV, 2002.

- OSTENFELD, L. T.; SVENDSEN, A.; SMEDSGAARD, J. Biochemical characterization of Ochratoxin A-Producing Strains of the Genus Penicillium. En: Applied and Environmental Microbiology. 2001, 67(8):3630-3635

- PONSONE, M.L.; COMBINA, M.; DALCERO, A.; CHULZE, S. Ochratoxin A and ochratoxigenic Aspergillus species in Argentinean wine grapes cultivated under organic and non organic systems. En: International Journal of Food Microbiology. 2007, 114:131-135.

- REBRIKOV, D.V.; TROFIMOV, D.Y. Real-time PCR: a review of approaches to data analysis. En: Applied Biochemistry and Microbiology. 2006, 42(5):455-463.

- SAMBROOK, J.; FRITSCH, E. F.; MAGNATIS, T. Molecular cloning: a laboratory manual. $2^{\circ}$ ed. New York: CSHL, 1989

- SELMA, M.; MARTÍNEZ-CULEBRAS, P.V.; AZNAR, R. Realtime PCR based procedures for detection and quantification of Aspergillus carbonarius in wine grapes. En: International Journal of Food Microbiology. 2008, 122:126-134.

- SERRA, R.; MENDOÇA, C.; VENÂCIO, A. Fungi and ochratoxin A detected in healthy grapes for wine production. En: Letters in Applied Microbiology. 2006, 42:42-47.

- SERRA, R.; BONVEHI, J. Occurence of ochratoxin A in cocoa products and chocolate. En: Journal of Agriculture and Food Chemistry. 2004, 52(20):6347-6352.

- VATINNO, R.; ARESTA, A.; ZAMBONIN, C.G.; PALMISANO, F. Determination of Ochratoxin A in green coffee beans by solidphase microextraction and liquid chromatography with fluorescence detection. En: Journal of Chromatography A. 2008, 1187(1):145150. 